\title{
Trialkylamine versus Trialkylphosphine: Catalytic Conjugate Addition of Alcohols to Alkyl Propiolates
}

\author{
David Tejedor, ${ }^{\mathrm{a}, \mathrm{b} *}$ Alicia Santos-Expósito, ${ }^{\mathrm{a}, \mathrm{b}}$ Gabriela Méndez-Abt, ${ }^{\mathrm{a}, \mathrm{b}}$ Catalina Ruiz-Pérez ${ }^{\mathrm{c}}$ and Fernando García- \\ Tellado ${ }^{\mathrm{a}, \mathrm{b} *}$ \\ a Instituto de Productos Naturales y Agrobiología, Consejo Superior de Investigaciones Científicas, Astrofísico Francisco Sánchez 3 , \\ 38206 La Laguna, Tenerife, Spain, \\ ${ }^{\mathrm{b}}$ Instituto Canario de Investigación del Cáncer (www.icic.es) \\ ${ }^{c}$ Departamento de Física Fundamental II, Universidad de La Laguna, Astrofísico Francisco Sánchez s/n, 38204 La Laguna, Tenerife, \\ Spain
}

Fax: (int)-34922260135.

E-mail: fgarcia@ipna.csic.es; dtejedor@ipna.csic.es

Received: The date will be inserted once the manuscript is accepted.

Abstract: The conjugate addition of activated propargylic alcohols to alkyl propiolates is shown to be catalyst-dependent. Whereas trialkyl amines catalyze the expected 1,4-adition of the alcohol on the alkynoate to give the $\beta$-alkoxyacrylate derivative, the trialkyl phosphine-catalyzed reaction affords densely functionalized bicyclic hexahydrofuro[2,3-b]furan derivatives. A mechanistic proposal for the phosphine-catalyzed addition of alcohols to alkyl propiolates according with these observations is advanced.

Keywords: Catalysis, Amines, Phosphorus, Bicyclic compounds, Alkynes.

The conjugate addition of alcohols to alkyl propiolates to generate the corresponding alkyl $\beta$ alkoxyacrylates derivatives 1 (Scheme 1$)^{1-3}$ has become a key component in a current methodology for the construction of oxacycles, ${ }^{4}$ specially, in the synthesis of complex polycyclic ether molecules. ${ }^{5}$ In spite of its synthetic relevance, the mechanism of this reaction has not been fully established. The reaction has been documented to take place under both trialkylamine ${ }^{1,2}$ and trialkylphosphine ${ }^{1,3}$ catalysis, and not surprisingly, a common nucleophile-catalyzed mechanism has been postulated for both processes. In the current accepted mechanistic proposal, the tertiary amine (or phosphine) acts as a nucleophilic catalyst, and not simply as a base, to trigger a controlled sequence of events entailing: 1) formation of the $\beta$-onium enolate intermediate $\mathbf{I}$; 2) alkoxide salt II formation by acid-base reaction of intermediate I (strong base) and the starting alcohol; 3) addition-elimination of alkoxide II onto the activated $\beta$ onium-acrylate I to give the corresponding $\beta$ alkoxyacrylate derivative $\mathbf{1}$ with catalyst liberation to reinitiate the catalytic cycle (Scheme 1). On the other hand, it is well known that the reaction of electron deficient internal alkynes under phosphine catalysis leads to umpolung nucleophilic additions to the $\alpha^{-}{ }^{6}$ or $\gamma-$ positions, ${ }^{7}$ but never under amine catalysis. Although this is a different situation than the catalytic addition over terminal activated alkynes, it is clear evidence that vinylammonium and vinylphosphonium salts may behave differently. ${ }^{8}$

In the course of our investigation dealing with the reactivity of alkyl propiolates and different electrophiles 9 in the presence of trialkylamines or trialkylphosphines we encountered some discrepancies that prompted us to further investigate the insights of these catalytic

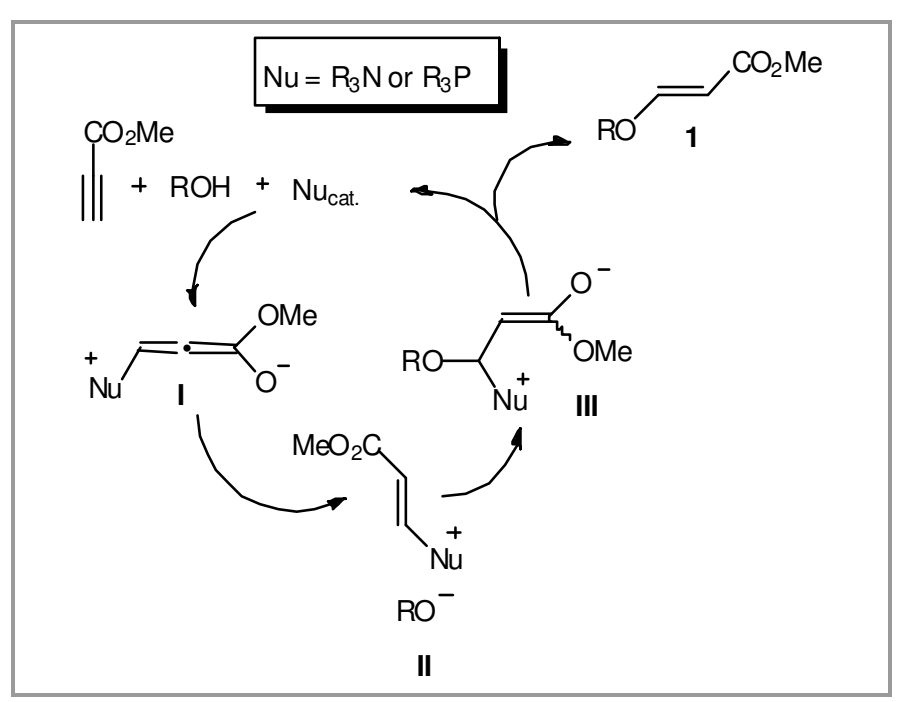

Scheme 1. Mechanistic proposal of the organocatalytic addition of alcohols to methyl propiolate.

processes. We first reported that alkyl propiolates and aliphatic aldehydes afford different products depending on the nature of the utilized catalyst (Scheme 2). ${ }^{9 a}$ When the appropriate zwitterionic intermediate I (Schemes 1 or 2 ) is generated in the absence of an alcohol or other sources of more acidic protons, it abstracts the proton from another propiolate molecule $(\mathrm{pKa}<18.8)^{10}$ to afford the ammonium or phosphonium acetylide salts II (Scheme 2). This newly formed nucleophilic species adds readily onto aliphatic aldehydes to generate the key alkoxide III. Notice that intermediate II in Scheme 1 and intermediate III in Scheme 2 differ in the nature of the alkoxide ion while they share in common their counterion. Interestingly, depending whether it is an ammonium or phosphonium salt, propargylic alkoxide III can evolve to form the enol ether $2($ cycle $\mathrm{a}, \mathrm{Nu}=\mathrm{N}$ ) through the reaction of the ion pair, or the 4,5-dihydrofuran derivatives 3 (cycle $b, \mathrm{Nu}=\mathrm{P}$ ) through the reaction of the alkoxide with a free starting alkynoate and the subsequent intramolecular Michael addition followed by protonation. ${ }^{11}$ Intrigued by these results we planned to study the catalytic conjugate addition of activated propargylic alcohols to propiolates. 


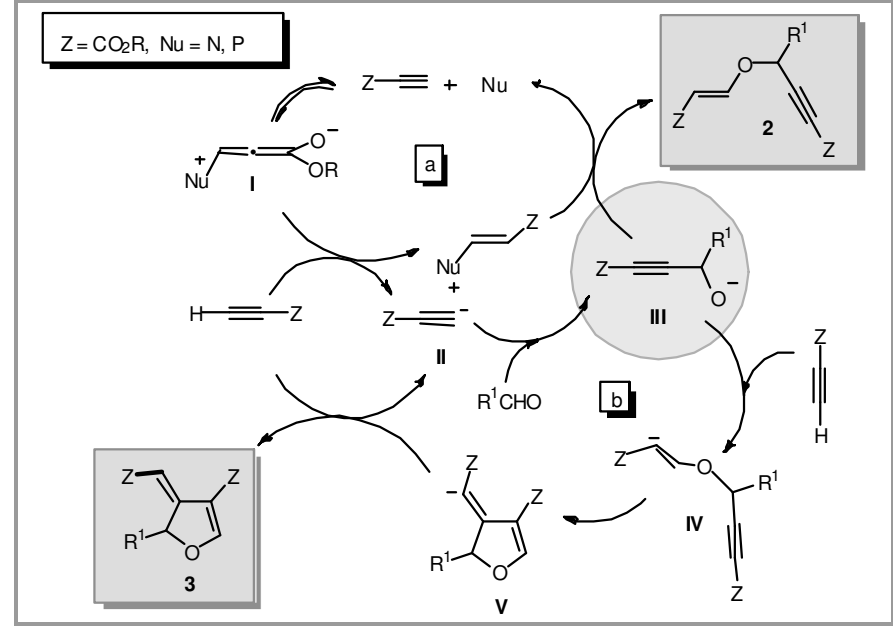

Scheme 2. Organocatalyzed reaction of alkyl propiolates with aliphatic aldehydes in the presence of tertiary amine (phosphine).

As expected, the reaction of activated propargylic alcohols $4 \mathbf{a}$ or $\mathbf{4 b}$ with methyl propiolate in the presence of catalytic amounts of triethylamine afforded the corresponding enol ethers 2a-b (Scheme 3), an interesting highly functionalized molecular scaffold that has found applications in the synthesis of various types of heterocycles. ${ }^{12}$ In fact, the same reaction products were obtained when other tertiary amines such as DABCO or Nmethyl morpholine (NMM) were used. ${ }^{13}$ This was in complete agreement with our previous results shown in Scheme 2 when the alkoxide ions were generated in situ after the addition of the acetylide salt to an aliphatic aldehyde instead of directly from the alcohol. Furthermore, these results are in accordance with what we would have predicted from bibliographic data. ${ }^{1,2}$

$$
\left.\right|_{\mathrm{CO}_{2} \mathrm{R}} ^{\mathrm{R}}
$$

4a $\mathrm{R}=\mathrm{CO}_{2} \mathrm{Et}, \mathrm{R}^{1}=\mathrm{H}$

4b $\mathrm{R}=\mathrm{CO}_{2} \mathrm{Me}, \mathrm{R}^{1}=\mathrm{i}-\mathrm{Pr}$

Scheme 3. $\mathrm{Et}_{3} \mathrm{~N}$-catalyzed addition of activated propargylic alcohols to methyl propiolate.

Interestingly, the same reaction of activated propargylic alcohols $\mathbf{4 a}$ or $\mathbf{4 b}$ with methyl propiolate, but this time in the presence of catalytic amounts of tributylphosphine, afforded exclusively the bicyclic hexahydrofuro[2,3-b]furan derivative $\mathbf{5 b}$ as a mixture of isomers (Scheme 4). ${ }^{14}$ In a parallel experiment, we observed that enol ether $\mathbf{2 b}$ could not be transformed into bicyclic $\mathbf{5 b}$ in the presence of a catalaytic amount of tributylphosphine.

Although the reaction may have minor synthetic relevance, the topology of product $\mathbf{5 b}$ claims for a different reaction pattern operating under these reaction condi-

tions. Observe that under these reaction conditions, the corresponding 4,5-dihydrofuran derivatives $\mathbf{3}$ do not form; in their place, a further elaborated different set of products is obtained.

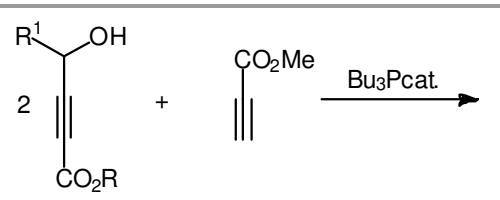

4a $\mathrm{R}=\mathrm{CO}_{2} \mathrm{Et}, \mathrm{R}^{1}=\mathrm{H}$

4b $\mathrm{R}=\mathrm{CO}_{2} \mathrm{Me}, \mathrm{R}^{1}=\mathrm{i}-\mathrm{Pr}$

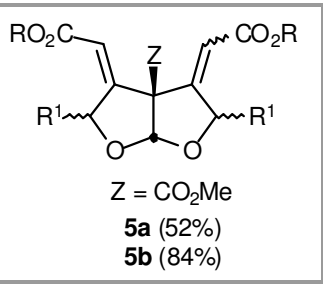

Scheme $4 . \mathrm{Bu}_{3} \mathrm{P}$-catalyzed addition of activated propargylic alcohols to methyl propiolate.

We reasoned that the bicyclic structure should form via a formal phosphine catalyzed [3+2] cycloaddition of the 4,5-dihydrofuran intermediate $\mathbf{3 b}$ with the propargyl substrate. This was confirmed when, in a different experiment, a mixture of $E$ and $Z$ 4,5-dihydrofuran $\mathbf{3 b}$ was made to react with the propargylic alcohol $\mathbf{4 b}$ in the presence of tributylphosphine and the same set of products $\mathbf{5 b}$ was obtained (Scheme 5). Interestingly, to the best of our knowledge, this is the first example of an organocatalytic formal [3+2] cycloaddition of propargylic alcohols with electrophilic alkenes. ${ }^{15}$ Furthermore, it was again confirmed that tertiary amines as $\mathrm{Et}_{3} \mathrm{~N}$ or DABCO did not catalyze this reaction.

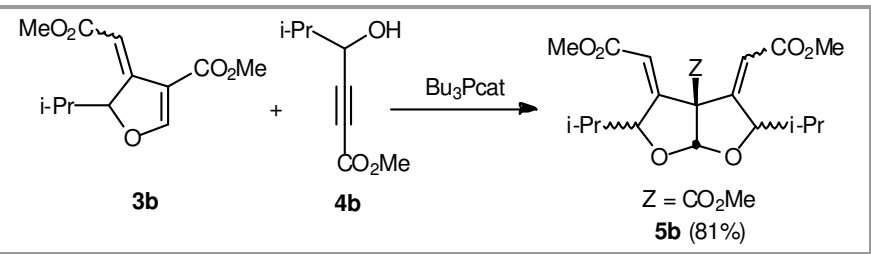

Scheme 5. $\mathrm{Bu}_{3} \mathrm{P}$-catalyzed addition of activated propargylic alcohol 4b to 4,5-dihydrofuran $\mathbf{3 b}$.

It is important to point out that propargylic enol ethers 2 are the expected products from an organocatalytic addition of propargylic alcohols to methyl propiolate that follows the mechanism shown in scheme $1 .{ }^{16}$ Therefore, the phosphine catalyzed version should proceed via an alternate mechanism that is able to account for the apparent discrepancies observed. Although it was not possible to observe any differences in the conjugated addition of the different alcohols studied up until now, the nature of the conjugated propargylic alcohol has revealed new and important information and is the key to these findings. Apparently, the propargylic alcohols possess a sufficiently reactive functionality (the activated alkyne unit) that enables the unexpected initial formation of the 4,5dihydrofuran intermediates through an intramolecular Michael addition (Scheme 2, conversion of $\mathbf{I V}$ into $\mathbf{V}){ }^{17}$

With these results on hand, the postulated mechanisms for the addition of alcohols to methyl propiolate depending on the nature of the catalyst are shown in Scheme 6. Intermediate II is common to both processes, but since vinylammonium and vinylphosphonium salts 
behave differently, when the catalyst is a tertiary phosphine the alkoxide ion is not capable to react with the corresponding vinylphosphonium. Instead, it reacts with another propiolate molecule to form the intermediate IV that leads to the final enol ether unless there is a more reactive functionality that prevents its formation.

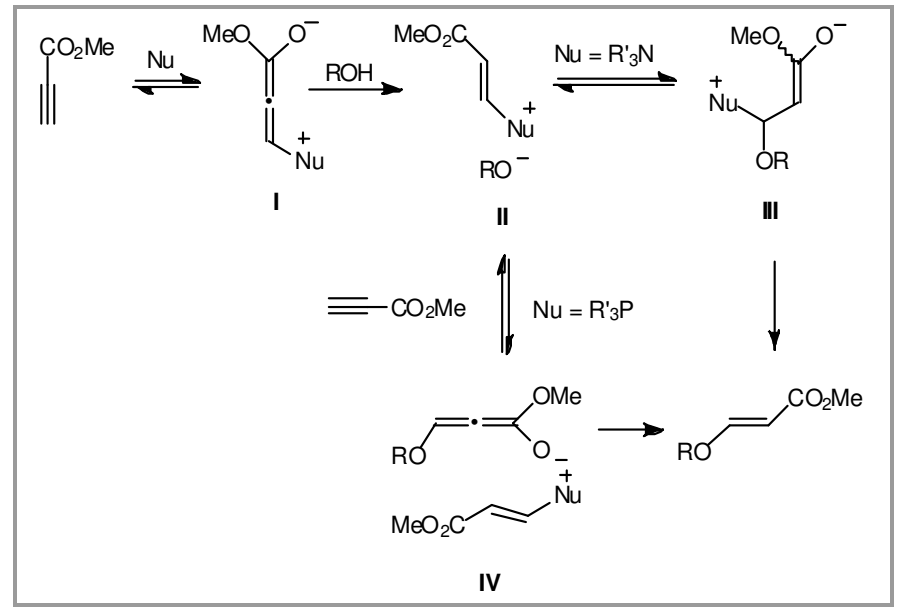

Scheme 6. Postulated addition of alcohols to methyl propiolate depending on the nature of the catalyst.

In summary, we have reported that the catalytic conjugated addition of activated propargylic alcohols to propiolates is clearly dependent on the nature of the catalyst. In light of these results, the mechanistic proposal for the phosphine-catalyzed addition of alcohols to alkyl propiolates should be revised according to Scheme 6 . This work will aid in the proper use of catalysts during the synthesis of $\beta$-alkoxyacrylates and related processes.

Experimental details for the $\mathrm{Et}_{3} \mathrm{~N}$-catalyzed addition of activated propargylic alcohols to methyl propiolate: Product 2a was synthesized from $\mathbf{4 a}$ as described in Scheme 3. A cooled $\left(0^{\circ} \mathrm{C}\right)$ solution of propargylic alcohol and methyl propiolate $\left(1.0 \mathrm{mmol}\right.$ of each) in $\mathrm{CH}_{2} \mathrm{Cl}_{2}(5 \mathrm{~mL})$ was stirred with $\mathrm{Et}_{3} \mathrm{~N}(0.2 \mathrm{mmol})$ until a TLC showed complete starting material disappearance. Solvent and excess reagents were removed under reduced pressure and the product was isolated by flash column chromatography (silica gel, n-hexane/EtOAc). ${ }^{1} \mathrm{H}$ $\mathrm{NMR}\left(\mathrm{CDCl}_{3}, 400 \mathrm{MHz}\right): \delta 1.30(\mathrm{t}, 3 \mathrm{H}, J=7.2 \mathrm{~Hz})$, 3.69 (s, 3H), 4.23 (q, 2H, $J=7.2 \mathrm{~Hz}), 4.62(\mathrm{~s}, 2 \mathrm{H}), 5.31$ $(\mathrm{d}, 1 \mathrm{H}, J=12.5 \mathrm{~Hz}), 7.52(\mathrm{~d}, 1 \mathrm{H}, J=12.5 \mathrm{~Hz}) .{ }^{13} \mathrm{C}$ NMR $\left(\mathrm{CDCl}_{3}, 100 \mathrm{MHz}\right): \delta 13.9,51.3,57.5,62.4,79.3$, 79.7, 98.6, 152.5, 160.2, 167.3. IR $\left(\mathrm{CHCl}_{3}, \mathrm{~cm}^{-1}\right)$ 3021.7, 2248.3, 1710.2, 1629.6, 1259.6, 1137.4. Anal. Calcd. for $\mathrm{C}_{10} \mathrm{H}_{12} \mathrm{O}_{5}: \mathrm{C}, 56.60 ; \mathrm{H}, 5.70$. Found: C, 56.61; H, 5.65. $\mathrm{MS}, \mathrm{m} / \mathrm{z}$ (relative intensities) $212(\mathrm{M}+, 21), 181(86)$, 156 (95), 139 (70), 125 (50), 67 (95), 66 (100), 55 (69).

\section{Experimental details for the $\mathrm{Bu}_{3} \mathrm{P}$-catalyzed addition} of activated propargylic alcohols to methyl propiolate: Product 5a was synthesized from $\mathbf{4 a}$ as described in Scheme 4. A cooled $\left(-78^{\circ} \mathrm{C}\right)$ solution of propargylic alcohol and methyl propiolate (1.0 mmol of each) in $\mathrm{CH}_{2} \mathrm{Cl}_{2}(5 \mathrm{~mL})$ was stirred with $\mathrm{Bu}_{3} \mathrm{P}(0.8 \mathrm{mmol})$ for a few minutes at $-78^{\circ} \mathrm{C}$ and allowed to react without fur- ther cooling for $1 \mathrm{~h}$ (lower amounts of $\mathrm{Bu}_{3} \mathrm{P}$ slow down the reaction while higher temperatures have a negative impact in the overall yield). After the reaction was completed, solvent and excess reagents were removed under reduced pressure. Product isolated by flash column chromatography as a mixture of two isomers (silica gel, n-hexane/EtOAc). Mixture of (2Z,2'Z; minor) and (2Z,2'E; major). Data for major isomer. ${ }^{1} \mathrm{H}$ NMR (CD$\left.\mathrm{Cl}_{3}, 500 \mathrm{MHz}\right): \delta 1.25(\mathrm{t}, 3 \mathrm{H}, J=6.9 \mathrm{~Hz}), 1.27(\mathrm{t}, 3 \mathrm{H}, J$ $=6.9 \mathrm{~Hz}), 3.75(\mathrm{~s}, 3 \mathrm{H}), 4.14-4.21(\mathrm{~m}, 4 \mathrm{H}), 4.59(\mathrm{dd}, 1 \mathrm{H}$, $J=15.0,2.0 \mathrm{~Hz}), 4.67(\mathrm{dd}, 1 \mathrm{H}, J=15.0,2.1 \mathrm{~Hz}), 5.09$ $(\mathrm{dd}, 1 \mathrm{H}, J=16.8,2.8 \mathrm{~Hz}), 5.18(\mathrm{dd}, 1 \mathrm{H}, J=16.8,2.7$ $\mathrm{Hz}), 5.80(\mathrm{~s}, 1 \mathrm{H}), 5.90(\mathrm{t}, 1 \mathrm{H}, J=2.0 \mathrm{~Hz}), 6.27(\mathrm{t}, 1 \mathrm{H}, J$ $=2.7 \mathrm{~Hz}) .{ }^{13} \mathrm{C} \mathrm{NMR}\left(\mathrm{CDCl}_{3}, 125 \mathrm{MHz}\right): \delta 14.06,14.07$, $52.9,60.5,61.0,67.5,71.6,73.1,113.1,114.2,117.5$, $155.9,156.0,165.2,165.8,168.1$. IR $\left(\mathrm{CHCl}_{3}, \mathrm{~cm}^{-1}\right)$ 3017.2, 1734.8, 1711.6, 1667.7, 1374.1, 1266.1, 1228.5, 1155.9. Anal. Calcd. for $\mathrm{C}_{16} \mathrm{H}_{20} \mathrm{O}_{8}$ : C, 56.47; H, 5.92. Found: C, 56.43; H, 6.03. MS, $m / z$ (relative intensities) 340 (M+, 6.0), 295 (61), 294 (100), 166 (69), 163 (55), 77 (49), 59 (38), 51 (35).

\section{Acknowledgment}

This research was supported by the Spanish Ministerio de Educación y Ciencia and the European Regional Development Fund (CTQ2005-09074-C02-02 and CTQ2008-06806-C02-02), the Spanish MSC ISCIII (RETICS RD06/0020/1046), CSIC (Proyecto Intramural Especial 200719) and Fundación Instituto Canario de Investigación del Cáncer (FICI-G.I.Nº8/2007).

\section{References}

(1) Inanaga, J.; Baba, Y.; Hanamoto, T. Chem. Lett. 1993, 241.

(2) (a) Winterfield, E. Chem. Ber. 1964, 97, 1952. (b) Ireland, R. E.; Wipf, P.; Xiang, J.-N. J. Org. Chem. 1991, 56, 3572.

(3) Methot, J. L.; Roush, W. R. Adv. Synth. Catal. 2004, 1035.

(4) Lee, E.; Tae, J. S.; Lee, C.; Park, C. M. Tetrahedron Lett. 1993, 34, 4831.

(5) For a recent example, see: (a) Inoue, M.; Miyazaki, K.; Ishihara, Y.; Tatami, A.; Ohnuma, Y.; Kawada, Y.; Komano, K.; Yamashita, S.; Lee, N.; Hirama, M. J. Am. Chem. Soc. 2006; 128, 9352. For selected reviews, see: (b) Inoue, M.; Hirama, M. Acc. Chem. Res. 2004, 37, 961. (c) Marmsäter F. P.; West, F. G. Chem. Eur. J. 2002, 8, 4346.

(6) Trost, B. M.; Dake, G. R. J. Am. Chem. Soc. 1997, 119, 7595.

(7) Lu, X.; Zhang, C.; Xu, Z. Acc. Chem. Res. 2001, 34, 535.

(8) For a recent and related example, see: Shi, Y.-L.; Shi, M. Org. Lett 2005, 7, 3057.

(9) (a) Tejedor, D.; García-Tellado, F.; Marrero-Tellado, J. J.; de Armas, P. Chem. Eur. J. 2003, 9, 3122. (b) Tejedor, D.; González-Cruz, D.; Sántos-Expósito, A.; Marrero-Tellado, J. J.; de Armas, P.; García-Tellado, F. Chem. Eur. J. 2005, 11, 3502. (c) Gonzalez-Cruz, D.; Tejedor, D.; de Armas, P.; Garcia-Tellado, F. Chem. Eur. J. 2007, 13, 4823. (d) Tejedor, D.; Santos-Expósito, A.; García-Tellado, F. Chem. Eur. J. 2007, 13, 1201. (e) Tejedor, D.; López-Tosco, S.; González-Platas, J; García-Tellado, F. J. Org. Chem. 2007, 72, 5454.

(10) Kresge, A. J.; Pruszynski, P. J. Org. Chem. 1991, 56, 4808.

(11) We have shown that under different reaction conditions 1,3-dioxolane derivatives can be obtained regardless of the catalyst used, see reference 9 a.

(12) (a) Tejedor, D.; González-Cruz, D.; García-Tellado, F.; Marrero-Tellado, J. J.; Rodríguez, M. L. J. Am. Chem. Soc. 
2004, 126, 8390. (b) Tejedor, D.; Santos-Expósito, A.; González-Cruz, D.; García-Tellado, F.; Marrero-Tellado, J. J. J. Org. Chem. 2005, 70, 1042.

(13) $\mathrm{The}_{3} \mathrm{~N}$ in $\mathrm{CH}_{2} \mathrm{Cl}_{2}$ proved to be the best catalytic system.

(14) Six different isomers were isolated with relative intensities 0.81:0.72:0.94:1.00:0.07:0.01 and identified on the basis of their NMR spectra and the X-ray analysis of one of the isomers.

(15) For a review of formal [3+2] cycloaddition of propargylic substrates: Yamazaki, S. Chem. Eur. J. 2008, 14, 6026.

(16) As long as the $\mathrm{R}^{1}$ substituent shown in Scheme 1 is an aliphatic group. It has been shown that activated propargylic alcohols bearing aromatic substituents isomerize to the corresponding alkenoates in the presence of tertiary amines. Sonye, J. P.; Koide, K. Org. Lett. 2006, 8, 199 and references cited therein.

(17) Unactivated propargylic alcohols behave as expected affording the corresponding product $\mathbf{1}$ (see ref. 1). 
Trialkylamine versus Trialkylphosphine: Catalytic Conjugate Addition of Alcohols to Alkyl Propiolates.

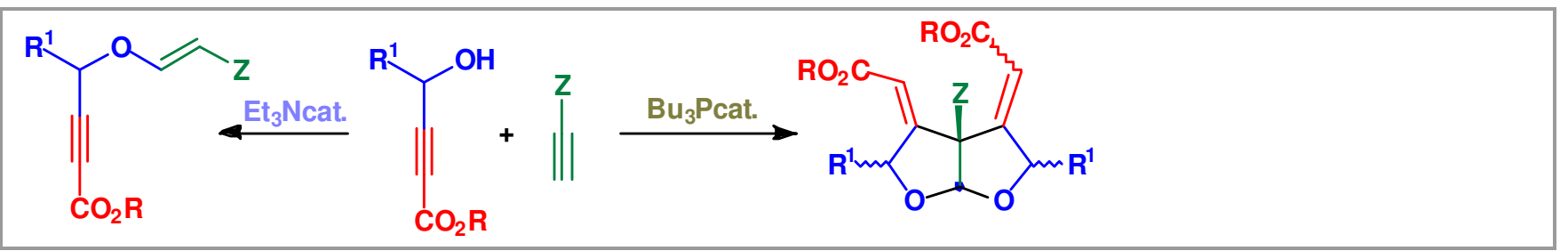

